5. Zhang J, Yu KF (1998) What's the relative risk? A method of correcting the odds ratio in cohort studies of common outcomes. JAMA 280: 1690-1691

6. DECODE Study Group; on behalf of the European Diabetes Epidemiology Group (2001) Glucose tolerance and cardiovascular mortality. Comparison of fasting and 2-hour diagnostic criteria. Arch Intern Med 161: 397-404

7. Tuomilehto J, Lindstrom J, Eriksson JG et al. (2001) Prevention of type 2 diabetes mellitus by changes in lifestyle among subjects with impaired glucose tolerance. N Engl J Med 344: 1343-1350

\section{Incidence of childhood Type I diabetes mellitus is increasing at all ages in Germany}

To the Editor: Incidence of Type I (insulin-dependent) diabetes mellitus in childhood seems to be increasing worldwide, and the increase is varying considerably between countries and even between geographic regions within the same country [1]. Pooled European data suggest that the highest rate of increase occurs in children under 5 years of age and that the increase is similar in boys and girls [1]. But there are conflicting results from different European regions [2, 3, 4, 5]. For Germany, recent age-specific and sex-specific incidence trends have not been reported so far. We conducted a long-term incidence study in the West German federal state of North Rhine-Westphalia for the period 1987-2000. The aims of this analysis were to estimate the most recent time trends of Type I diabetes in children between 0 and 14 years of age in West Germany, and in particular to assess potential differences in the temporal trend of the incidence between age groups and between sexes.

In 1993, we started a prospective childhood Type I diabetes incidence registry in a geographically well defined region within the federal state of North Rhine-Westphalia, as part of the Eurodiab Ace research network $[2,6]$. According to the EURODIAB ACE protocol, newly diagnosed children with diabetes are prospectively registered by a hospital-based active surveillance system contacting every month all paediatric departments and diabetes-specialized internal departments in the study region, in total 41 hospitals. Details of the study design, data collection and first results for the period 1993-1994 have been reported elsewhere [6]. This surveillance system is well established in Germany for monitoring rare paediatric diseases and has been used to estimate the national incidence of Type I diabetes in children $0-4$ years of age [7]. In addition to prospectively collected data for the period 1993-2000, all newly diagnosed children with diabetes for the period 1987-1992 were retrospectively assessed from hospital records. Inquiries among paediatric, internal and general medical practices and among members of the diabetic patients' association were used as secondary independent data source. Completeness of ascertainment was estimated by the capture-recapture-method. Annual population data were available from official statistics. The average risk population during 1987-2000 was about 400000 children. Point and interval estimates (95\%-CI) of incidence rates (per 100000 person-years) were based on Poisson distribution. Age- and sex-standardized incidences were estimated by the direct method with equal weights for subgroups defined by sex and age groups $(0-4,5-9$, and $10-14$ years). Time trends were assessed by Poisson regression analysis.

For the period 1987-2000, a total of 715 newly diagnosed diabetic children between 0 and 14 years of age ( 376 boys, 339 girls) were registered. Completeness of ascertainment was estimated
8. Branchtein L, Schmidt MI, Matos MC, Yamashita T, Pousada JM, Duncan BB (2000) Short stature and gestational diabetes in Brazil. Brazilian Gestational Diabetes Study Group. Diabetologia 43: 848-851

Corresponding author: A. A. Jacob Reichelt, Av. Alegrete, 507/701, 90460-100 Porto Alegre, Rio Grande do Sul, Brazil, e-mail: aajacob@zaz.com.br

as $90.1 \%$ (95\% -CI: 86.8-93.6\% ). The overall age-standardized and sex-standardized incidence rate was 13.1 per 100000 person-years (95\%-CI: 12.1-14.1). The age-standardized rates for boys $(13.5 ; 12.1-14.8)$ and for girls $(12.7 ; 11.4-14.1)$ were similar $(p=0.440)$. The incidence increased with age $(p<0.001)$, the sex-standardized rates for the age groups $0-4(n=169), 5-9$ $(n=259)$ and $10-14$ years $(n=287)$ were $8.9(7.6-10.3), 14.0$ (12.3-15.7), and 16.4 (14.5-18.2), respectively.

The annual age-standardized and sex-standardized incidence rates ranged between 7.6 in 1989 and 17.5 in 1993. Over the fourteen-year period, a statistically significant average annual incidence increase of $3.6 \%(1.7-5.5 \%)$ was estimated, adjusted for age and sex. Time trend analysis based on ascertainment corrected annual rates instead of observed rates resulted in a similar estimate of the average annual increase $(3.4 \%$, $1.6-5.3 \%)$. Compared with the incidence in 1987, the overall incidence increase during the fourteen-year period according to the Poisson model was $58 \%$. There was no difference in the time trend between sexes $(p=0.499)$, the age-adjusted average annual incidence increase was $4.3 \%$ per year $(1.5-7.2 \%)$ in girls and $3.0 \%$ per year $(0.4-5.6 \%)$ in boys. The incidence rose at a similar rate in all age groups $(p=0.948)$, the sex-adjusted age-specific annual increases were: $0-4$ years: $4.0 \%$ per year $(0.1-8.1 \%), 5-9: 3.2 \%$ per year $(0.1-6.4 \%)$ and $10-14: 3.7 \%$ per year $(0.7-6.8 \%)$ (Fig. 1 ).

The incidence patterns in Figure 1 might suggest that Poisson models with an increasing trend until 1993-1994 and a constant incidence level thereafter could be more appropriate than models with a homogeneous trend over the whole study period. However, there are several arguments against change points in the time trends. First, Poisson models accounting for respective change points in time trend did not significantly improve the data fit in each of the three age groups as well as in females $(p>0.07)$. Secondly, in the male and the overall group, models with an increasing trend until 1993 and a constant incidence level thereafter improved the fit $(p<0.05)$ but the good fit of these models was likely to be due to singular peak incidences in 1993 and 1995. After excluding the peak incidences from trend analysis the change point models were no longer superior to the homogeneous trend model $(p>0.1)$. For a rare disease in a limited risk population such outlying peak incidences could arise from random variation. Thirdly, shortterm piecewise fitting of trends could mask the true long-term time trend. In Finland for example, the incidence increase of Type I diabetes was erroneously believed to have levelled off at the beginning of the $1990 \mathrm{~s}$, because there had been no trend apparent during 1987-1992 [3].

The mean incidence in 1987-2000 in the study region within North Rhine-Westphalia in West Germany was in accordance with the reported incidence in a more southerly part of the country and was higher than estimates reported from the former German Democratic Republic for the late 1980 s [8]. The 


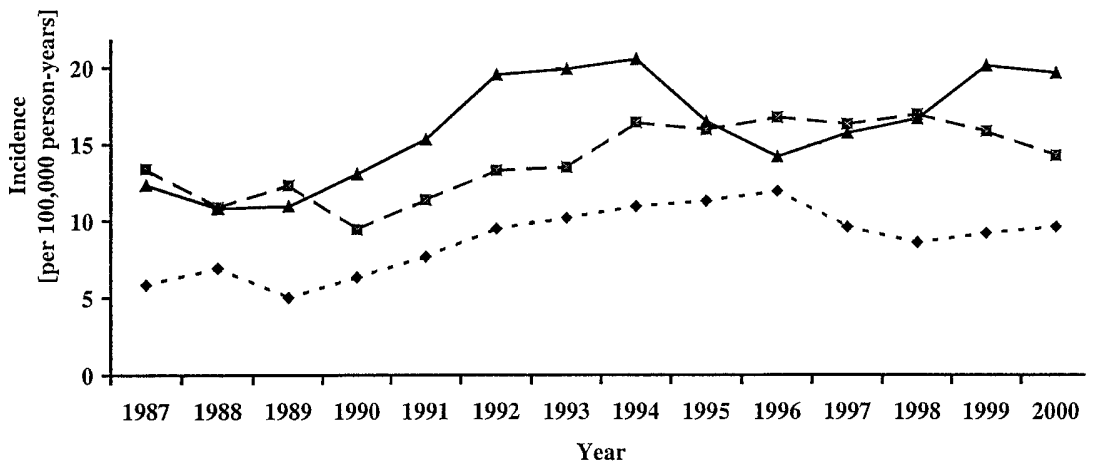

Fig. 1. Smoothed (3-year moving average) sex-standardized incidence rates of childhood Type I diabetes in North RhineWestphalia, Germany, by age group (1987-2000). $\bullet$ 0-4 years, 5-9 years, $\Delta$ 10-14 years

peak incidences in 1993 and 1995 above 17 per 100000 personyears are the highest rates ever reported for Germany.

The time trend analysis has shown that over the past fourteen-year period the incidence of childhood Type I diabetes has continued to rise on average by $3.6 \%$ per year in the study region within North Rhine-Westphalia. This observed annual increase in this western part of Germany corresponded to the reported trend from a more southerly region of Germany (3.6\% per year during 1987-1998, 8) and to the mean European trend (3.4\% per year during 1989-1994, 1). In line with pooled European data and regional data from Oxford, United Kingdom, and Switzerland [1, 2, 4], but unlike in Finland [3], there was no significant difference in the time trend between sexes. But in contrast to the pooled European data and regional data from Oxford, Finland and Switzerland [1, 2, 3, 4], in this study the increase in incidence has been observed to occur in all ages with a similar rate. This has recently been reported also from Yorkshire and Scotland, United Kingdom [5]. The observed differences in age- and sex-specific incidence trends between countries have to be confirmed by ongoing longterm studies.

The underlying causes of the striking incidence increase in Germany as well as in other European countries are not known. However, increases in incidence rates over relatively short time periods are not likely to be explained by genetic factors and point therefore to the importance of environmental factors in the causation of the disease $[1,2,5]$. The observed homogeneous age-independent temporal trend could support the hypothesis that the occurrence of Type I diabetes is influenced by environmental exposures at all ages.

Acknowledgements. This study was supported by the German Federal Ministry of Health, the Ministry of Sciences and Research of the Federal State of North Rhine-Westphalia, and the European Community Concerted Actions EURODIAB ACE (Contract BMH1-CT92-0043) and EURODIAB TIGER (Contract BMH4-CT96-0577).

J. Rosenbauer, A. Icks, D. Schmitter, G. Giani

\section{References}

1. EURODIAB ACE Study Group (2000) Variation and trends in incidence of childhood diabetes in Europe. Lancet 355: 873-876

2. Gardner SG, Bingley PJ, Sawtell PA, Weeks S, Gale EAM, the Bart's-Oxford Study Group (1997) Rising incidence of insulin dependent diabetes in children aged under 5 years in the Oxford region: time trend analysis. BMJ 315: 713-717

3. Karvonen M, Pitkäniemi J, Tuomilehto J, and the Finnish Childhood Diabetes Registry Group (1999) The onset age of Type 1 diabetes in Finnish children has become younger. Diabetes Care 22: 1066-1070

4. Schoenle EJ, Lang-Muritano M, Geschwend S et al. (2001) Epidemiology of Type I diabetes mellitus in Switzerland: steep rise in incidence in under 5 year old children in the past decade. Diabetologia 44: 286-289

5. Feltbower RG, McKinney PA, Bodansky HJ (2000) Rising incidence of childhood diabetes is seen at all ages and in urban and rural settings in Yorkshire, United Kingdom. Diabetologia 43: 682-684

6. Rosenbauer J, Icks A, Giani G (1998) Typ 1-Diabetes bei Kindern und Jugendlichen - prospektive Inzidenzstudie in der Region Düsseldorf. Kinderärztliche Praxis 1: 15-25

7. Rosenbauer J, Herzig P, von Kries R, Neu A, Giani G (1999) Temporal, seasonal, and geographical incidence patterns of Type I diabetes mellitus in children under 5 years of age in Germany. Diabetologia 42: 1055-1059

8. Neu A, Ehehalt S, Willasch A, Kehrer M, Hub R, Ranke MB (2001) Rising incidence of Type 1 diabetes in Germany. 12 -Year trend analysis in children $0-14$ years of age. Diabetes Care 24: 785-786

Corresponding author: J. Rosenbauer, German Diabetes Research Institute, Department of Biometrics and Epidemiology, Auf'm Hennekamp 65, D-40225 Düsseldorf, Germany, e-mail: rosenb@ddfi.uni-duesseldorf.de 